\section{La gráfica urbana como herramienta comunicativa y transformadora. Casos: Colombia y Argentina}

Katherine Muñoz Osorio *

Resumen: En este artículo se presentan los recorridos de tres experiencias artísticas y comunitarias, en las que por medio del trabajo colectivo en espacios rurales y urbanos, se lograron transformar las realidades sociales, utilizando la gráfica urbana como medio de vinculación y expresión.

Palabras clave: Comunicación - Cultura - Desarrollo - Gráfica urbana - Transformación social.

[Resúmenes en inglés y portugués en la página 176]

${ }^{(*)}$ Comunicadora social y Periodista de la Universidad del Valle (Colombia). Magister en Planificación y gestión de procesos comunicacionales (Universidad Nacional de La Plata). Facilitadora pedagógica digital del Ministerio de Educación de la Ciudad Autónoma de Buenos Aires. Gestora en distintos procesos comunitarios y culturales del campo social, gráfico y audiovisual.

\title{
Introducción
}

La aparición de murales como expresiones dotadas de estética y sentido, se han vuelto cada vez más recurrentes en diferentes espacios que cumpliendo funciones comunicativas manifiestan distintos procesos culturales, políticos y sociales. Los mismos se han ganado un lugar en el campo de la discusión artística, potenciándose como herramientas de transformación que van más allá de los muros y de los límites urbanos.

El graffiti, término divulgado en medios académicos a mediados del siglo XIX por el arqueólogo Raffaele Garrucci (Gimeno y Mandingorra, 1997) es hoy una de los dispositivos fundamentales para facilitar el empoderamiento de las comunidades frente a sus distintas problemáticas. Estos se valen de diversas manifestaciones y técnicas agrupadas en el concepto de gráfica urbana como pueden ser: el stencil, los stickers, los fanzines, las firmas -tags-, con el uso de aerosoles, entre otros, para expresar el sentir, las necesidades, las denuncias y rescatar su cultura. 
En el mundo se conocen casos de artistas activistas como Bansky, quien es famoso por hacer una fuerte crítica a las políticas capitalistas, a la guerra -The walled off Hotel, hotel inaugurado en Cisjordania con la peor vista del mundo a causa de los bombardeos-, y al maltrato animal -Sirens of the Lambs, un camión lleno de animales de peluche que van rumbo al matadero-. En América Latina también existen artistas y colectivos que han dedicado su obra a dar voz a sus comunidades como Daniel Poetalatas de México, quien retrata a los habitantes de su pueblo. Junto a él proyecto Afuera de Perú denuncia la explotación minera; o el Proyecto Fauna de Mar del Plata, Argentina, que visibiliza la contaminación ambiental.

Es así como la cultura, expresada en la gráfica urbana, se convierte en un,

Recurso estratégico fundamental a la hora de gestionar proyectos y organizaciones actuales, que posean no solo un nuevo impacto sobre el desarrollo de la propia actividad, sino que, además, en virtud de su capacidad "transversal", se transformen en una dimensión fundamental para la productividad de un conjunto mayor de sectores y esferas asociadas, que sus acepciones históricas no eran capaces de sostener y alimentar (Maccari y Montiel, 2012, pp. 35).

En este artículo se expondrán tres experiencias de gestión de distintos contextos que, a través de la gráfica urbana, lograron comunicarse con su entorno y transformar su realidad, relatando la memoria y la historia de la comunidad en sus muros.

\section{Gráfica Mestiza}

Cali es una ciudad colombiana de más de 2 millones de habitantes donde convergen personas de diferentes regiones y que por su geografía de valle -montaña y mar-, alberga distintas etnias y culturas. En la actualidad, esta diversidad se hace evidente a través de las distintas expresiones que emergen de espacios como el teatro, la biblioteca, el centro cultural, la escuela y el barrio.

Durante el 2009 se llevó a cabo la implementación de las políticas de cultura a través del programa Industrias Culturales Cali y, por primera vez, los fondos de capital semilla y emprendimiento abrían su espectro empresarial para dar cabida a diversidad de proyectos y expresiones emergentes del entretenimiento, la gastronomía, el diseño, las editoriales, la música, y los festivales que destacan la riqueza cultural de la ciudad. "La ciudad cumple un papel básico para el desarrollo, ya que tiene características que le permiten jugar de elemento de transacción de flujos materiales e inmateriales entre personas, ideas, mercancías y valores" (Bonet, 2008, p. 72).

Aprovechando la coyuntura, es en este contexto donde nace Gráfica Mestiza, ideado por el diseñador gráfico Jesús David Rodríguez, como medio de divulgación desde un ámbito universitario lleno graffitis, murales y publicaciones que relatan la lucha estudiantil de décadas, en defensa de la educación pública y que ahora trascende a los muros de la Ciudad con un amplio panorama de piezas tanto artísticas como políticas. 
El proyecto se propone dar a conocer el trabajo de artistas locales y formar redes a nivel latinoamericano, aprovechando el potencial de Internet es por esto que sus productos principales son una página web y una publicación anual -digital e impresa-, con las que se busca llegar cada vez a más públicos interesados en el tema.

La Gráfica Mestiza se concibe como:

Un espacio alternativo de comunicación para difundir las nuevas propuestas artísticas urbanas que se están gestando en Latinoamérica. Un medio de socialización, discusión e intercambio de conocimientos técnicos, artísticos, sociales y culturales, donde tienen cabida los expertos, nuevos artistas y todos aquellos interesados en conocer las manifestaciones culturales que se están produciendo en la patria grande (...). Intentando reconocer la identidad gráfica y cultural de nuestra ciudad, de Colombia y Latinoamérica llegamos al término "mestizaje gráfico", similar al de la música mestiza, en donde se pueden encontrar y disfrutar las mezclas y simbiosis que representan los diferentes artistas latinoamericanos, sea graffiti, street art, arte urbano o arte callejero (Sección "Quiénes somos" de la antigua página web de Gráfica Mestiza, 2010).

En sus inicios contaba solamente con una cuenta de Flickr y de Facebook, a través de las cuales comenzaron a seguir artistas y publicaciones similares. Estas dos plataformas le sirvieron para hacer un diagnóstico de personas y lugares donde la gráfica urbana contaba con visibilidad, además de conocer otras revistas -con similares enfoques o no-, que podrían convertirse en sus próximas aliadas. Mediante redes sociales empezaron a contactar artistas, a presentar actividades, a enterarse de eventos en otros lugares y cuando se presentó la oportunidad de asistir presencialmente, ya el proyecto era conocido por muchos. Ahora Gráfica Mestiza cuenta con más de 49.700 seguidores en Facebook y continuas visitas a su página web y tienda virtual, lo que genera un flujo constante de contenidos e intercambios y les proporcionó más visibilidad en los motores de búsqueda, además de la posibilidad de vender pauta publicitaria en sus medios para poder costear sus actividades. Hoy en día, las redes sociales son la manera más eficiente y económica de comunicar, si se las usa correctamente. Si se entiende la dinámica de los likes, seguidores, etiquetas, las tendencias, entre otros, se pueden cruzar nuevas fronteras y los límites territoriales ya no serán un obstáculo.

Gráfica Mestiza ha publicado tres revistas, un libro y dos álbumes de stickers, destacando el trabajo de cientos de artistas latinoamericanos, que además de centrar sus obras en el desarrollo de una estética propia y característica han sido parte de procesos sociales dentro de sus propias comunidades, aportando a procesos culturales y de formación en diferentes países del continente.

Además de las publicaciones, este proyecto ha podido acompañar la gestión de prácticas locales donde la gráfica urbana ha jugado un rol fundamental como herramienta de comunicación y transformación, logrando el trabajo colectivo en distintos contextos y el empoderamiento de diferentes comunidades, con muros que denuncian injusticias sociales y que han logrado trascender los límites territoriales. Es así como el rol de la cultura se torna un activo estratégico por sus alcances como acción colectiva y por su potencialidad 
para la recuperación de los lazos de asociatividad, sumando así, a la definición de un tipo de desarrollo humano, instancia en la que los individuos son tenidos en cuenta como "sujetos del desarrollo" (Rey, 2002, pp. 40). También cuenta con una tienda en su página web donde se promocionan artículos de diseño -bolsos, libros, camisetas-, que los mismos artistas producen de manera paralela a los murales, como una fuente de ingreso adicional. Conjuntamente logró abrir un espacio físico con el mismo fin: "La Grafitería" tienda/café, que es aprovechado para realizar reuniones, talleres, exposiciones y pequeños eventos que la posicionan como un lugar de referencia de la gráfica urbana en la ciudad de Cali garantizando el financiamiento de los integrantes del colectivo y sus producciones, como es el caso de la segunda edición del libro álbum de stickers mestizos, que en su convocatoria recibió más de 500 diseños de distintos artistas latinoamericanos.

Para que un proyecto logre tener impacto y sea coherente, cualquiera que sea su propósito, debe ser desarrollado colectivamente. Aunque la idea surja de una sola persona, para su ejecución es necesaria la intervención y participación de colegas que aporten sus puntos de vista, su experiencia, habilidades y creatividad.

La comunicación alternativa para el desarrollo democrático es la expansión y el equilibrio en el acceso de la gente al proceso de comunicación y en su participación en el mismo empleando los medios -masivos, interpersonales y mixtos-, para asegurar, además del avance tecnológico y del bienestar material, la justicia social, la libertad para todos y el gobierno de la mayoría (Beltrán, 2005, pp. 15).

En el trabajo colectivo logran ponerse en juego distintos saberes que nutren los proyectos y que permiten tener un panorama más amplio de las necesidades y potencialidades en el campo de acción. Esta forma de trabajo permitió a Gráfica Mestiza expandirse a otros países. A pesar de que en su mayoría funciona virtualmente, gracias a la página web, se vincularon escritores, fotógrafos y gestores en Colombia, Ecuador, Costa Rica y Argentina principalmente, para dar a conocer la labor de artistas, participar en eventos, generar espacios de exposición, intercambio e intervenciones, en distintas ciudades de Latinoamérica. Además de la autogestión, la participación en convocatorias y fondos toma gran importancia actualmente, dada la apertura de los países frente a las industrias culturales y al emprendimiento, como parte de su proyecto de crecimiento y desarrollo económico. En Colombia existen fondos privados como Ventures y Destapa Futuro, que ofrecen capital semilla a emprendimientos de toda índole, con un acompañamiento profesional y con requisitos formales que debe cumplir toda empresa -constitución legal y comercial, plan de negocios, entre otros-. No obstante, y a pesar de ser una gran oportunidad económica y de aprendizaje, estos espacios siguen estando muy enfocados a procesos más industriales quedando así la producción artística en desventaja, en términos de producción y ganancias económicas. De todas formas, por parte del Estado, están disponibles el Fondo de Desarrollo Cinematográfico, los Fondos Mixtos de Cultura y las convocatorias de Estímulos de cada provincia.

En el Informe sobre Desarrollo Humano (PNUD 2004), se define a la cultura "ya no como algo que inspira, enaltece y educa, sino como un complejo campo de actividades humanas 
que debe estar en el centro mismo de la economía, la política y todos los servicios sociales" (Yúdice, 2005, pp. 44), y en esa misma línea surge la idea de "desarrollo humano sustentable como la necesidad de sostener todas las formas de capital y recursos (físicos, humanos, financieros, ambientales) como una precondición para asegurar las necesidades de futuras generaciones" (Yúdice, 2005, pp. 42).

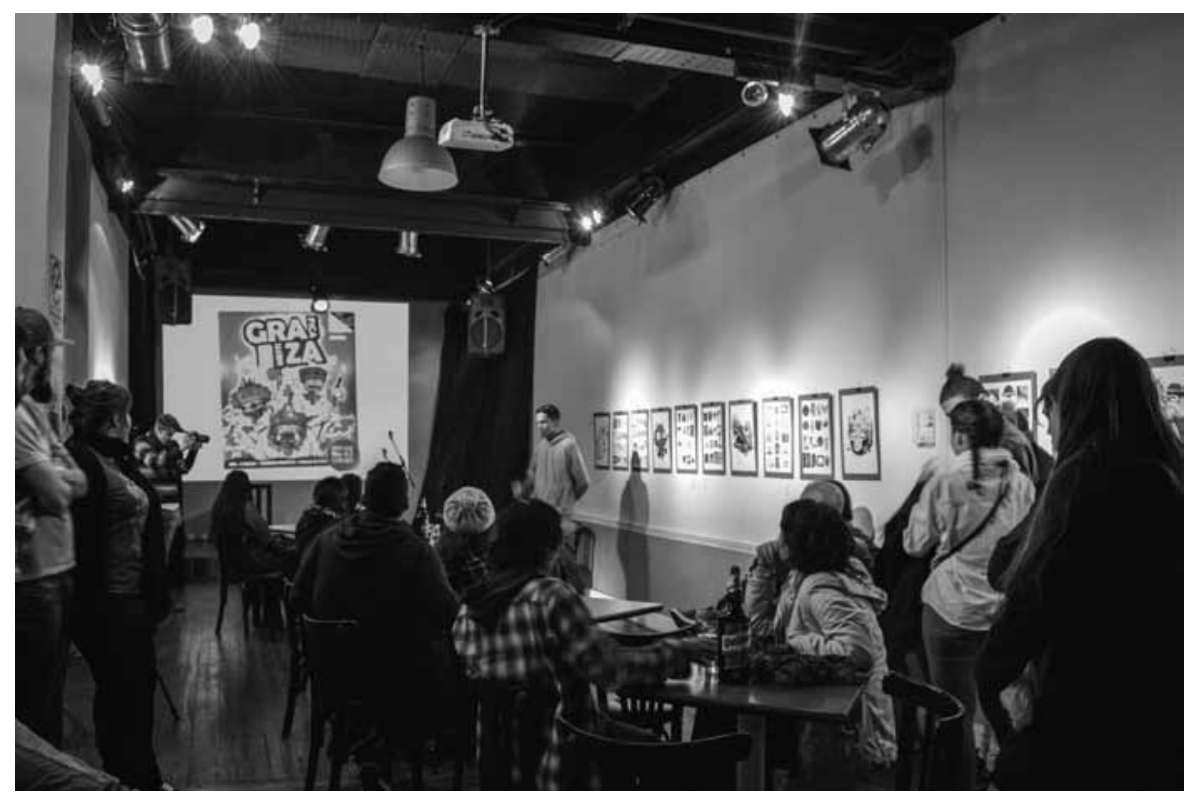

Figura 1. Exposición de stickers y lanzamiento del libro-álbum Sticker Mestizo. Centro Cultural El Quetzal, Bs. As., Argentina (Muñoz, 2016).

Mediante estas convocatorias privadas y públicas, Gráfica Mestiza ha podido acceder a mayores recursos para financiar la impresión de publicaciones y viajes de intercambio que posibilitan el desarrollo de eventos y el fortalecimiento del proyecto. Este fue el caso de la gira realizada en Argentina, en la cual se pudieron generar nuevos vínculos a través de la visita a espacios culturales, universidades, tiendas editoriales y proyectos gráficos y sociales. En Argentina, a pesar de no tener una ley de cultura como tal, en los últimos años se vivió un fuerte proceso de asociativismo y cooperativización -de fábricas recuperadas, medios y otros emprendimientos-, además del surgimiento de iniciativas comunitarias gracias a la implementación de la Ley de Medios (2009). También, existen fondos específicos para este sector como Puntos de Cultura, Mecenazgo Cultural y una interesante propuesta gubernamental materializada en los Distritos de las Artes - diseño, tecnológico, deportivo y 
audiovisual-, que concentran y asesoran el desarrollo de proyectos generando espacios de intercambio y producción de distintos sectores.

\section{Minga Artística de Muralistas de los Pueblos ${ }^{1}$}

Qué mejor estrategia que una minga para convocar a la comunidad al trabajo colectivo, que en este caso, busca cambiar la cara de un municipio rural, integrar a sus habitantes y promover el turismo.

El gestor Alberto Velasco ${ }^{2}$ fue el responsable de haber reunido cerca de 200 personas para cambiarle la cara a Toribío, el pueblo más azotado por la guerrilla de las Farc en toda su historia. Desde 1979, este municipio ubicado entre las montañas del norte del Cauca (Colombia) ha sufrido más de 600 hostigamientos y esta guerrilla se lo ha tomado un centenar de veces. Como resultado, en el casco urbano de Toribío se encuentran varias casas destruidas que se han convertido en trincheras desde las que la Policía y el Ejército responden a los continuos ataques, viéndose afectadas directamente las familias de campesinos e indígenas que allí habitan. Por tal motivo, fue necesario unir esfuerzos y gestionar la realización de La Minga, convocando artistas externos, actores sociales, entidades gubernamentales, guardia indígena y a los mismos habitantes para hacer una creativa denuncia pública, porque como lo expresa el mismo Alberto: "pintar es un acto político que significa apropiarse". Con esta movida se logró hacer un llamado al cese al fuego que trascendió las fronteras del territorio para tener visibilidad en los medios ${ }^{3}$.

Este paisaje de desolación cambió radicalmente en octubre de 2013. Durante una semana, más de 40 artistas de Italia, México, Ecuador y varias ciudades de Colombia pintaron más de 130 murales alusivos a los mitos de los indígenas Nasa y a su lucha por resistir a una guerra que se ha ensañado contra ellos. Velasco cuenta que los policías querían impedirles que pintaran sus trincheras, pero cuando vieron a los niños del pueblo decididos a intervenir esos espacios empezaron a retroceder. "Lo que no habían logrado los guerrilleros con las balas lo hicimos nosotros con nuestras herramientas"4.

La minga inició con un ritual de "abrir camino" y luego se recibieron las orientaciones de los indígenas mayores y las autoridades tradicionales, esto con el fin de que todo lo que se plasme en los murales sea participativo. A partir de estas orientaciones los artistas hicieron los respectivos bocetos de las obras a realizar para luego socializarlos hasta lograr el consenso. En las noches de la minga se desarrollaron actividades culturales, deportivas y video foros, con la intención de hacer lúdica la jornada durante la semana y de integrar a otras personas de la población.

Al terminar los murales se hizo una entrega formal a la comunidad del casco urbano, haciendo un recorrido por las locaciones intervenidas. Para la clausura se realizó un acto cultural en la plaza pública, con la participación de las autoridades tradicionales y espirituales. Esta minga se pronunció contra todos los frentes armados presentes en la zona (ejército, guerrilla y paramilitares) y logró poner en la agenda de los medios nacionales e internacionales (virtuales en su mayoría) este territorio tan olvidado por el Estado colombiano.

La Minga de Muralistas de los Pueblos, logró una réplica de su proyecto en otra provincia y se denomina Pinto Putumayo. En esencia persigue el mismo objetivo de acercar el arte 
a zonas rurales y darle voz a través de los murales a comunidades que sufren el flagelo de la guerra.

En este caso, Pinto Putumayo encaró una importante movida en la pasada inundación de Mocoa (capital de Putumayo), donde el desbordamiento de 3 ríos dejó 358 hectáreas afectadas y más de 300 personas muertas ${ }^{5}$. El proyecto convocó a artistas de distintas áreas para realizar brigadas en 4 albergues y acompañar a niños y mujeres, intentando devolverles una sonrisa en medio de la tragedia.

Estos logros demuestran que los proyectos nunca deben estar aislados de las realidades de su contexto. Es mucho más valioso cuando un proyecto surge de una necesidad o inquietud y busca resolverla.

Cuando los actores involucrados no tienen el protagonismo adecuado o nivel de liderazgo y empoderamiento en el proyecto, se pone en peligro la sostenibilidad de las intervenciones. Dependiendo del tipo de proyecto, la sociedad civil puede ser uno de los interesados más importantes que deben permanecer activos durante toda la vida del proyecto ${ }^{6}$.

En esa medida será legitimado y contará con mayor apoyo y vinculación de parte de la comunidad. Los moradores de Toribío se apropiaron del muralismo como una herramienta de expresión importante para denunciar los atropellos y crímenes sufridos durante años a manos de los distintos grupos armados. "Nuestros ancestros marcaban en las rocas los sitios sagrados y los límites del territorio. Nosotros hacemos lo mismo con los murales. Es un acto de resistencia y de ejercicio ancestral de gobierno sobre esta tierra" (Revista Arcadia, 2016, s/p) ${ }^{7}$.

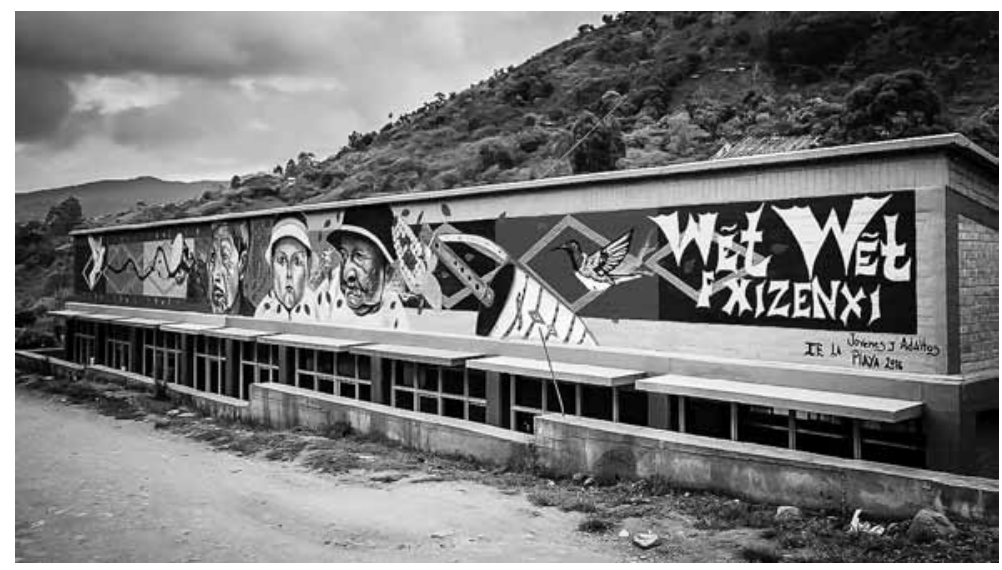

Figura 2. Institución Educativa La Playa. Artistas: Grupo de estudiantes adultos. Foto: tomada de la web del Centro de Memoria Histórica del Gobierno de Colombia. Cauca, Colombia (2016). 
La Playa es una vereda de casas de ladrillo y bahareque construidas a lado y lado de la carretera. Sus habitantes cultivan hortalizas y crían vacas, cerdos y gallinas. Sobre la fachada del colegio, junto a la vía sin pavimentar, resalta el mural de Óscar Arango, un artista de Cali. El rostro de un niño, una anciana y un hombre de ceño adusto dominan la parte superior de la pared. La mujer se llama Salvadora Silva. Es la más anciana de La Playa. Tiene 103 años y aún les da de comer a las gallinas y camina por el pueblo apoyada en un bastón rústico de madera. El hombre es Honorio Chate, un líder indígena y actual presidente de la junta comunal. Las mujeres de la vereda ayudaron a pintar el maíz capio, el colibrí, la flauta y las palabras Wët Wët Fxizenxi ${ }^{8}$, que completan el cuadro. "Esta pintura es un homenaje a nuestros mayores, que son quienes guían a la comunidad y les enseñan las tradiciones a los niños", explica un líder indígena a través de un megáfono?.

La Minga dejó alrededor de 100 pinturas realizadas por más de 40 artistas, entre los que se encuentra la misma comunidad. Pinturas que constituyen un mecanismo cultural y comunicativo, que permite reflexionar.

La comunicación pensada como hecho cultural, como proceso de producción de sentidos, nos da la oportunidad de situarnos en procesos de creación. Nos permite situarnos en instancias de re significación de la realidad. En momentos en que podemos producir nuevos sentidos que nos permiten comprender más profundamente "cómo estamos en el mundo", cómo es el mundo en el que estamos, y cómo es el mundo en el que queremos habitar (Arrúa, 2009, pp. 80).

\section{Volver a Habitar}

Luxor es un artista que comenzó a intervenir paredes de la ciudad de La Plata (Buenos Aires, Argentina), en el 2010. Él concibe sus pinturas en el espacio público como graffiti y como mural al mismo tiempo debido a las características del soporte y su narratividad. Asimismo, ve en el uso de este tipo de expresión gráfica, la resistencia y la canalización de una disputa simbólica y la posibilidad de interpelar, no sólo al transeúnte, sino también a otros a intervenir ese mismo espacio generando un diálogo con otras obras y graffitis ${ }^{10}$. $Y$ es que al transitar por los barrios platenses se siente la legitimidad que tiene el artista entre su comunidad porque además de pintar, Luxor ha gestado el encuentro entre vecinos, la apropiación de los espacios públicos como punto de encuentro y la auto gestión a través del apoyo de los emprendimientos barriales, propiciando un acceso más democrático al arte y la cultura. Aquí,

El concepto de desarrollo humano (...) subraya la ampliación progresiva de las oportunidades y capacidades de las personas, individual y colectivamente consideradas, como un modo de hacer posible la libertad efectiva de las personas $y$, por tanto, una vía para consolidar sus derechos. (Rey, 2008, pp. 39).

La Plata es la capital de la provincia de Buenos Aires, una ciudad reconocida por sus planificadas calles diagonales y su majestuosa catedral ubicada en el centro, cuyas cúpulas 
logran verse desde la distancia. A pesar de esto, en abril del 2013 muchos de sus barrios se vieron afectados por una trágica inundación. De aquí nace Volver a Habitar como un proyecto que busca darle voz a los afectados y del que hicieron parte un periodista, un fotógrafo, un músico y Luxor, quienes recorrieron la Ciudad generando una pieza artística de gran formato en cada barrio y una serie de micro documentales que relatan la situación de sus habitantes.

La obra consiste una serie gráfica de cuidadores con poderes mágicos para cada barrio que, luego de la charla con vecinos, fueron pintados en la fachada de algunas casas donde hubiese fallecido un familiar. El proceso de intervención no solo dio como resultado bellos murales sino que también sirvió para que los vecinos se ayudaran mutuamente y se apropiaran de la restauración de las fachadas de sus casas. Además, posibilitó descubrir las cifras reales de muertos y desastres causados por la inundación.

El proyecto resalta la idea de "restaurar comunidad" a partir de la realización de un mural, el cual aparece como excusa y como un "ejercicio de memoria". Es decir, el proyecto intenta generar lazos con los vecinos, construir espacios de encuentro, dar a conocer historias de vida, además de registrar las consecuencias de la inundación. A partir de la labor realizada desde Volver a Habitar se visualiza una fuerte idea de volver a tejer y rearmar lazos colectivos (Capasso, 2018, s/p).

Más allá del aspecto artístico, este proyecto motivó la acción colectiva de los afectados y demás vecinos. Junto a ello visibilizó la magnitud de la tragedia -89 muertos y más de 300 mil afectados-, y dio una nueva cara y esperanza a la Ciudad con los ocho grandes protectores pintados por Luxor para que la gente pudiera volver a habitar sus hogares.

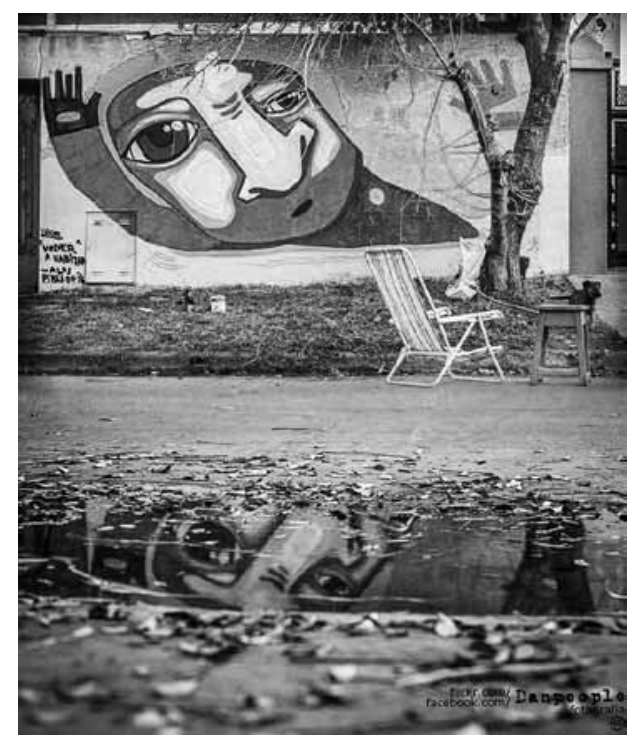

Figura 3. A los pibes de 76 (Luxor en casa de "Marcelo y Mercedes", La Plata, Bs As, Argentina, 2013). Foto: Danpeople. 
Actualmente, Luxor sigue llevando arte a los barrios, haciendo de La Plata un museo a cielo abierto del que hacen parte los vecinos, defendiendo día a día en su quehacer la idea de democratizar el arte. La tragedia que los convocó en sus inicios, ahora los motiva para dar vida a un nuevo proyecto que sirve como plataforma para artistas de distintos formatos y que ofrece acceso a toda la sociedad a un sinnúmero de murales que harán parte del paisaje y el embellecimiento platense.

Para legitimar un proyecto dentro de la comunidad es importante hacerla partícipe en distintos niveles. Algunos harán parte orgánica del proyecto y otros realizarán sus aportes específicos para cierta actividad. Es por esto que en Volver a Habitar, los fondos recaudados por crowfunding -a través de la plataforma Ideame-, eran provenientes en su mayoría de los mismos habitantes de La Plata -9 mil pesos, hoy alrededor de 300 USD-. Asimismo, los vecinos afectados lavaron y pintaron las fachadas de sus casas, aportando a la recuperación del barrio y haciendo parte de su propio proceso. Por otro lado, emprendimientos locales apoyaron la iniciativa haciendo donaciones en productos tangibles como la pintura para los murales elaborados por Luxor. Cada actor social desde su posición y posibilidades se vinculó al proyecto y a su propio proceso de construcción colectiva, colaborando y generando una red que se fortalece cada día y que ha permitido el desarrollo de nuevas iniciativas.

Otra propuesta que vale la pena destacar y que va en la misma línea es el proyecto Pintó la Isla, el cual surgió a partir de unos talleres de derechos humanos en la escuela 24 de Isla Maciel, en Avellaneda, donde los alumnos terminaron haciendo un graffiti para expresar sus inquietudes y que ahora tiene gran impacto en toda la comunidad, con la idea de ser también un museo a cielo abierto y embellecer el barrio como atractivo turístico, quizás respondiendo un poco al principio de gentrificación que busca mejorar la calidad de vida de sus habitantes y que otros sectores de la sociedad pongan el foco en el barrio como sucede con el barrio La Boca en Buenos Aires.

\section{Algunas conclusiones}

Luego de todo este recorrido es necesario resaltar los logros de las experiencias narradas, citando algunos aprendizajes a través de cuatro ejes que se articulan constantemente, como son: la comunicación, la gráfica urbana, las herramientas digitales y la vinculación con la comunidad.

En primer lugar, la comunicación es uno de los objetivos fundamentales de tres los proyectos y para lograrlo, tuvieron en cuenta a sus destinatarios y los recursos con los que contaban, que en este caso son las herramientas digitales y la gráfica urbana como gran producto comunicacional.

La gráfica urbana tiene la ventaja de convertirse en un lenguaje universal que puede transmitir un mensaje a personas de distintas edades y condiciones sociales y en este proceso, cada uno de los proyectos ha dialogado con los distintos actores vinculados. En el caso de Gráfica Mestiza, siempre ha sostenido una comunicación horizontal con los artistas para generar productos colectivamente y en función de educar públicos interesados en todas las manifestaciones en torno al tema. Tal como lo planteó Luis Ramiro Beltrán, quien 
formuló un modelo de comunicación horizontal, cifrado en el acceso, el diálogo y la participación entendidos como factores interdependientes.

La comunicación es el proceso de interacción social democrática que se basa sobre el intercambio de símbolos por los cuales los seres humanos comparten voluntariamente sus experiencias bajo condiciones de acceso libre e igualitario, diálogo y participación (Beltrán, 2005, pp. 15).

Por su parte, La Minga hizo partícipes a los campesinos de los contenidos y la producción de murales con los que hicieron visibles sus problemáticas. Finalmente, Volver a Habitar trabajó según las necesidades de su comunidad y logró vincularla fortaleciendo los lazos entre vecinos. Aplicando los conceptos de Susan Sontang (2006) sobre la imagen, aquí la gráfica urbana se convierte en un recurso para la memoria, los murales pasan a formar parte de la memoria colectiva -a pesar de su fugacidad-, y a relatar la historia de nuestras comunidades. Es por esto que,

El desafío en el campo de la Comunicación / Desarrollo, es poner cauces a la comunidad, para disparar la palabra y construir nuevos sentidos que den lugar a otros valores y modos de estar en el mundo (Arrúa, 2009, pp. 79).

Es necesario que los actores sociales sean los constructores de su propia realidad y que la comunicación sea una herramienta para lograr esta transformación. El uso de la gráfica urbana en los distintos proyectos ayudó a crear un público más consciente de sus propias realidades e inquietudes logrando darle voz a diversas comunidades y situaciones posicionando al graffiti y el muralismo como herramientas poderosas de comunicación, que poco tienen que ver con el estigma vandálico que han cargado durante años.

Las herramientas digitales han sido de gran importancia debido al actual contexto y a las potencialidades que ofrecen. Las redes sociales y demás plataformas fueron mecanismos que ayudaron a los proyectos a trascender fronteras y barreras territoriales y económicas, llevando la cultura y la gráfica, específicamente, más allá de los muros.

La cultura, comprendida más allá de una noción artística humanística, incluyendo la tecnología y la ciencia, es parte de un concepto de cultura ampliado, abarcativo y global (...), en el que la apertura de la modernidad es fundamental para avanzar (Bonet, 2009, pp. 34).

Sus logros sólo fueron posibles gracias al trabajo en red y con la comunidad, lo cual además es fundamental para garantizar la continuidad en el tiempo, el mejoramiento de los procesos y la sostenibilidad. Es aquí donde las competencias digitales cobran importancia para la consecución de recursos económicos y a su vez, para la optimización de los mismos, debido a los beneficios que ofrecen a la hora de comunicar, hacer publicidad, generar nuevos contactos, trabajar a distancia, gestionar y producir. Esto facilita que los procesos tengan mayor alcance, continuidad, no se desgasten, y más aún, que los artistas puedan vivir y subsistir de lo que les gusta y saben hacer, que puedan sacarle el mayor provecho a 
su trabajo y que sus obras sean valoradas, destacando el trabajo cultural como lo conciben Maccari y Montiel, como "una herramienta (...), que permita a creadores, emprendedores y responsables de proyectos poder retomar algo de aquella integralidad del oficio cultural y concebirse como trabajadores del ámbito de la cultura y de la creatividad" (Maccari y Montiel, 2012, pp. 34).

En el mejor de los casos, estas iniciativas pueden llegar a convertirse en modelos sustentables y sostenibles en términos de emprendimiento, que puedan dejar de depender de fondos económicos y subsidios, iniciativas que surgen desde la base social con la intención de aportar y mejorar su realidad, en el que los individuos son sujetos del desarrollo (Rey, 2002) y la cultura prevalece sobre los estándares hegemónicos y se convierte en una poderosa herramienta de transformación social. "La cultura no es, pues, un instrumento del progreso material: es el fin y el objetivo del desarrollo, entendido en el sentido de realización de la existencia humana en todas sus formas y en toda su plenitud" (UNESCO, 1997). Y en el caso de las tres experiencias aquí descritas, la gráfica urbana fue el instrumento para narrar de manera colectiva la memoria, la cultura y la historia de los territorios y su gente.

\section{Notas}

1. Primera Minga Artística de Muralistas de los Pueblos, municipio de Toribío Cauca, en el marco del IV Encuentro Cultural Álvaro Ulcue Chocue, 2013. KWE'SX KIWE BITE'JN. 2. El hombre de los murales (2015, marzo 29) ¡Pacifista! [Revista en línea]. Disponible en http://pacifista.co/el-hombre-de-los-murales/

3. Fotos: Minga de Muralistas de los Pueblos: "Pintando Resistencia" en Colombia (2013, octubre 27) Global Voices [Revista en línea]. Disponible en http://es.globalvoicesonline. org/2013/10/27/minga-de-muralistas-de-los-pueblos-pintando-resistencia-en-colombia/ 4. Op. Cit

5. Cifra de muertos por avalancha en Mocoa asciende a 134 (2017, abril 8) Diario El País [Diario en línea]. Disponible en http://www.elpais.com.co/colombia/cifra-de-muertospor-avalancha-en-mocoa-asciende-a-314.html

6. Curso de Gestión de Proyectos de Desarrollo - BID, Módulo de Introducción a la gestión del proyecto, pag. 36.

7. Memoria y Resistencia: En el pueblo que sufrió más de 700 ataques guerrilleros (2016, octubre 26) Revista Arcadia [Revista en línea]. Disponible en http://www.revistaarcadia. com/periodismo-cultural---revista-arcadia/articulo/toribio-vivio-mas-de-700-ataquesguerrilleros $/ 57231$

8. "Wët wët fxizenxi representa la unión familiar, la paz y el respeto a los mayores y la parte cultural de la comunidad por lo que se incluye la música y los tejidos". Centro Nacional de Memoria Histórica. Página we: http://centrodememoriahistorica.gov.co/micrositios/ minga-muralista/tacueyo.html

9. Idem

10. Idem

11. La Plata: "Volver a Habitar" (2013, julio 2) AnRed, Agencia de Noticias Red Acción [Revista en línea]. Disponible en http://www.anred.org/spip.php?article6314 


\section{Referencias Bibliográficas}

Arrúa, V. (2009). “Modalidades de conocimiento en Prácticas de Planificación y Gestión de la Comunicación: Análisis de experiencias del Programa de Unidad de Prácticas y Producción de Conocimiento". Maestría en Planificación y Gestión de la Comunicación. PLANGESCO. Facultad de Periodismo y Comunicación Social. Universidad Nacional de La Plata.

Arrueta, Brunet y Guzmán (Comp.) (2010). La Comunicación como Objeto de Estudio. Fadeccos. Argentina.

Beltrán, L.R. (1993). “Comunicación para el Desarrollo en Latinoamérica. Una evaluación sucinta al cabo de cuarenta años”. Discurso inaugural de la IV Mesa Redonda sobre Comunicación y Desarrollo. IPAL. Lima, Perú.

Bourdieu, P. (1997). Capital Cultural, Escuela y Espacio Social. Buenos Aires. Buenos Aires, Argentina. Siglo XXI Editores.

Castoriadis, C. (2004). Sujeto y Verdad en el Mundo Histórico - Social. México. Fondo de Cultura Económica.

Capasso, V. (2018). "Después de la inundación. Una propuesta para volver a habitar el espacio”. VII Jornadas de Jóvenes Investigadores. Facultad de Bellas Artes (FBA), Universidad Nacional de La Plata (UNLP).

Ceraso, C. (2008). Sembrando mi Tierra de Futuro. Comunicación, planificación y gestión para el desarrollo local. Unidad de Prácticas y Producción de Conocimiento. Facultad de Periodismo y Comunicación social. Universidad Nacional de La Plata.

Dallera, O. (2009). La Sociedad como Sistema de Comunicación. Buenos Aires, Argentina. Editorial Biblos.

Foucault, M. (2003). Vigilar y Castigar. Buenos Aires. Buenos Aires, Argentina. Siglo XXI Editores.

Gimeno, F. y Mandingorra, M. (1997). Los Muros tienen la Palabra: materiales para una historia del graffiti. Universidad de Valencia. Citado en: RODRIGUEZ, J. (2011). Análisis Gráfico del Post-graffiti en Cali. Tesis de Grado. Diseño Gráfico. Universidad del Valle. Disponible en: http://www.graficamestiza.com/index.php/actualidad/investigacion/105analisis- grafico-del-post-graffiti

Hopenhayn, M. (2003). "Educación, Comunicación y Cultura en la Sociedad de la Información: perspectiva latinoamericana”. Buenos Aires, Argentina. En Revista de la CEPAL 81.

Maccari y Montiel. (2012). Gestión Cultural para el Desarrollo. Buenos Aires, Argentina. Ed. Ariel.

Morin, E. (2006). Tierra Patria. Buenos Aires, Argentina. Ed. Nueva Visión.

Muñoz, K. (2018). "Guía de Gestión: Paquete de herramientas para desarrollar proyectos”. Maestría en Planificación y Gestión de la Comunicación. PLANGESCO. Facultad de Periodismo y Comunicación Social. Universidad Nacional de La Plata. Disponible en: https://www.dropbox.com/s/b9607av315clzza/Guia_de_Gestion_KMO_Web. pdf?dl=0

Sachs, W. (Ed.) (1996). Diccionario del desarrollo: Una guía del conocimiento como poder. Buenos Aires, Argentina. Ed. PRATEC.

Sontang, S. (2006). Sobre la Fotografía. México. Ed. Alfaguara. 
Stahl, J. (2009). Street Art. China. Ed. HFullmann.

Williams, R. (1981). Sociología de la cultura. Buenos Aires, Argentina. Ed. Paidós Comunicación.

\section{Referencias audiovisuales}

Gráfica Mestiza: Gira Argentina (2016). https://www.youtube.com/watch?v=Nmshbkgs LOY\& $=4 \mathrm{~s}$

Luxor: Charla TEDxPaseodelBosque "Democratizando el Arte" (2014). https://www.you

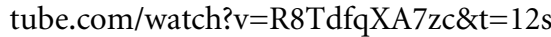

Volver a Habitar: Caso Los Hornos (2013). https://www.youtube.com/watch?v=KIaT4 nGDI84\&t $=134 \mathrm{~s}$

Minga Muralistas de los pueblos: Muralismo en el territorio Nasa (2013). https://www.you tube.com/watch? $=$ GpwlFEbPtFE

Abstract: This article presents the development of three communitarian and artistic experiences, in which social realities were transformed through collective work in rural and urban spaces using urban graphics as a means of expression and connection.

Keywords: Communication - Culture - Development - Urban graphics - Social transformation.

Resumo: Este artigo apresenta as trajetórias de três experiências artísticas e comunitárias nas quais, por meio do trabalho coletivo em espaços rurais e urbanos, foi possível transformar a realidade social utilizando a arte urbana como forma de interação e expressão.

Palavras chave: Comunicação - Cultura - Desenvolvimento - Arte urbana - Transformação social.

[Las traducciones de los abstracts fueron supervisadas por el autor de cada artículo] 